\title{
Prediction of the mechanical response of cardiac alternans by using an electromechanical model of human ventricular myocytes
}

Jun Ik Park and Ki Moo Lim* (1)

${ }^{*}$ Correspondence: kmlim@kumoh.ac.kr Department of IT Convergence Engineering, Kumoh National Institute of Technology, 61 Daehak-ro, Gumi, Gyeongbuk 39177, Republic of Korea (c) The Author(s) 2019. This article is distributed under the terms of the Creative Commons Attribution 4.0 International License (http://creativecommons.org/licenses/by/4.0/), which permits unrestricted use, distribution, and reproduction in any medium, provided you give appropriate credit to the original author(s) and the source, provide a link to the Creative Commons license, and indicate if changes were made. The Creative Commons Public Domain Dedication waiver (http://creativecommons.org/publi cdomain/zero/1.0/) applies to the data made available in this article, unless otherwise stated.
Results: As the BCL was reduced from 1000 to 200 ms at 30 ms increments, mechanical alternans, as well as electrical alternans, were observed. At this time, the myocardial diastolic tension increased, and the contractile ATP consumption rate remained greater than zero even in the resting state. Furthermore, the time of peak tension, equivalent cell length, and contractile ATP consumption rate were all reduced. There are two tendencies that endocardial, mid-myocardial, and epicardial cells have the maximum amplitude of tension and the peak systolic tension begins to appear at a high rate under the isometric condition at a particular BCL.

Conclusions: We observed mechanical alternans of ventricular myocytes as well as electrical alternans, and identified unstable conditions associated with mechanical alternans. We also determined the amount of $B C L$ given to each ventricular cell to generate stable and high tension state in the case of isometric contraction.

Keywords: Human ventricular myocyte, Alternans, Basic cycle length, Simulation study, Excitation-contraction coupling model 


\section{Introduction}

Alternans with opposite phase is associated with electrotonic coupling and conduction velocity, as well as the appearance of a slope in the action potential duration (APD) restitution curve [1-3]. Discordant alternans is also related to arrhythmogenesis because action potentials (APs) from adjacent ventricular cells are alternating out-of-phase which amplifies repolarization gradients, promotes conduction block, and aids in reentrant excitation [4-6]. The occurrence and complexity of re-entrant arrhythmia have a positive correlation with the number of islands of spatially discordant APD alternans [7]. Furthermore, T-wave alternans is reasonable to analyze susceptibility to ventricular arrhythmias $[8,9]$. Therefore, analysis of alternans in the ventricle is very important.

At the cellular level, instabilities of membrane potential and calcium cycling can cause APD and calcium transient alternans, which are a function of pacing rate. Voltage-driven alternans shows steep APD restitution slope, and calcium-driven alternans is related to two factors: one is the release of calcium from sarcoplasmic reticulum (SR), and the other is the reduced capability of clearing calcium in cytosol. These two factors are related to pulsus alternans and T-wave alternans in heart failure [10-12]. Alternans can also arise from small fractional releases under conditions where the ability of the SR to sequester $\mathrm{Ca}^{2+}$ is low [13].

At the organ level, monophasic AP alternans is always related to left ventricular pressure alternans [14]. Especially, the left ventricular ejection fraction of a patient with alternans considerably decreases [15]. The mechanics of each myocyte can connect between subcellular events and ventricular activities [16].

Although quantitative analyses of electrical alternans and mechanical alternans, which can be concerned with ventricular diseases, are important, previous studies have focused on electrical alternans. It also lacks quantitative analysis of cellular mechanical alternans, which may affect organ-level ventricular mechanics according to various basic cycle lengths (BCLs). In addition, clinical studies are time-consuming and less cost-efficient. Therefore, we used an excitation-contraction (E-C) coupling model of human ventricular cells to quantitatively analyze the electromechanical alternans of ventricular cells according to a lot of BCLs (from 1000 to $200 \mathrm{~ms}$ at $30 \mathrm{~ms}$ increments).

\section{Methods}

Mechanically contracting ventricular cells exhibit the following physiological mechanisms. First, the AP of the myocytes activates voltage-activated channel in the T-tubule to release calcium from the SR into the cytosol. This causes the binding of calcium and troponin $\mathrm{C}$ followed by myocyte contraction cycle due to sliding of myofilaments (actin and myosin). Finally, the contractile protein movement creates cross-bridge cycling which leads to the development of active tension in the myocyte. In order to implement the contraction mechanism of the ventricular cells as described above, we recently developed human ventricular myocytes models based on three valid models [17-19]. We succeeded in quantitatively predicting the cellular mechanics by this model [20-22]. In this study, we used calcium transient obtained from the electrophysiological model of the human ventricular cells as input into the contractile myofilament dynamics model (see Fig. 1). 


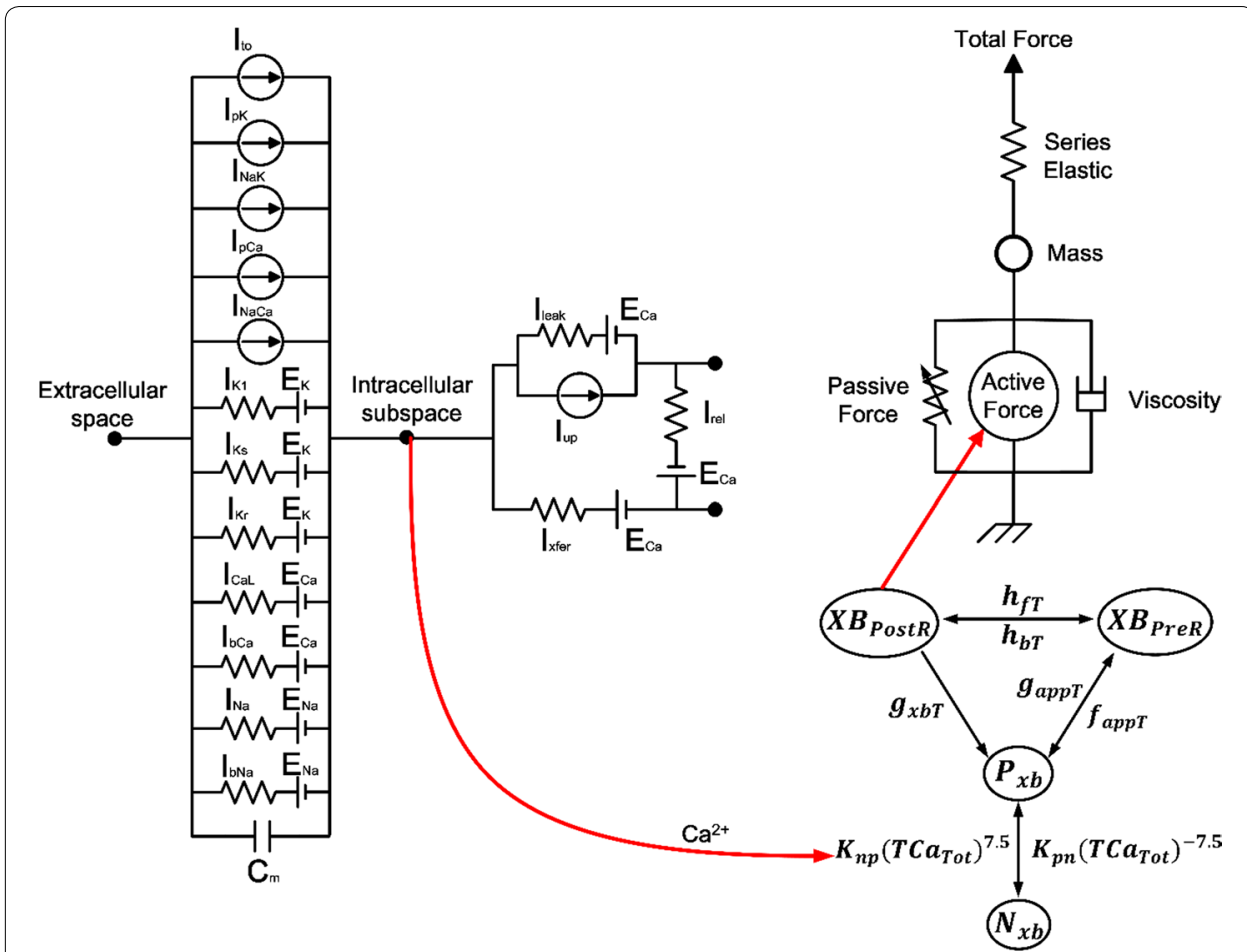

Fig. 1 Schematic diagram of excitation-contraction coupling model of ventricular cell. The left diagram represents a human ventricular cell model with electrophysiological characteristics that mimic the ion exchange phenomenon through the cell membrane of myocytes. I to is the transient outward $\mathrm{K}^{+}$current, $I_{\text {pK }}$ is the plateau $\mathrm{K}^{+}$pump current, $I_{\mathrm{NaK}}$ is the $\mathrm{Na}^{+}-\mathrm{K}^{+}$ion exchanger current, $I_{\mathrm{pCa}}$ is plateau $\mathrm{Ca}^{2+}$ pump current, and $I_{\mathrm{NaCa}}$ is the $\mathrm{Na}^{+}-\mathrm{Ca}^{2+}$ ion exchanger current. $E_{\mathrm{k}^{\prime}} E_{\mathrm{Ca}^{\prime}}$ and $E_{\mathrm{Na}}$ are the equilibrium potentials of $\mathrm{K}^{+}, \mathrm{Ca}^{2+}$, and $\mathrm{Na}^{+}$ions, respectively. $C_{m}$ is the ventricular cell membrane capacitance in the unit surface area. $I_{\mathrm{K} 1}$ is the inward rectifier $\mathrm{K}_{1}$ current, $I_{\mathrm{Ks}}$ is the slow delayed rectifier $\mathrm{K}^{+}$current, $I_{\mathrm{K} 1}$ is the rapid delayed rectifier $\mathrm{K}^{+}$current, $I_{\mathrm{CaL}}$ is the L-type inward $\mathrm{Ca}^{2+}$ current, $I_{\mathrm{bCa}}$ denotes the background $\mathrm{Ca}^{2+}$ current, $\mathrm{b}_{\mathrm{bNa}}$ is the background $\mathrm{Na}^{+}$current, and $I_{\mathrm{Na}}$ is the fast inward $\mathrm{Na}^{+}$current. $I_{\text {rel }}$ is the release $\mathrm{Ca}^{2+}$ current from the sarcoplasmic reticulum (SR), I leak is the leakage $\mathrm{Ca}^{2+}$ current from the $\mathrm{SR}$, and $I_{\text {up }}$ is the $\mathrm{Ca}^{2+}$ uptake current in the SR. The right diagram represents the cardiac myofilament model to simulate mechanical responses of myocytes. $N_{\mathrm{xb}}$ and $P_{\mathrm{xb}}$ are non-permissive and permissive confirmations of regulatory proteins, respectively, and $\mathrm{XB}_{\text {PreR }}$ and $\mathrm{XB}_{\text {PostR }}$ represent the probability that the cross-bridge is in the pre/post-rotated force-generating state. $g_{\mathrm{xb}}$ is the detachment transition rate with consuming ATP, $h_{\mathrm{fT}}$ and $h_{\mathrm{bT}}$ are the forward and backward transition rates, $f_{\text {аррт }}$ and $g_{\text {аap }}$ are the cross-bridge attachment rate of transition and reverse rate. $K_{\mathrm{np}}$ and $K_{\mathrm{pn}}$ are transition rates for the fraction of permissive, $K_{\mathrm{np}}\left(\mathrm{TCa}_{\mathrm{Tot}}\right)^{7.5}$ is the forward rate of the non-permissive to permissive transition in the opposite direction, and $k_{\mathrm{pn}}\left(\mathrm{TCa}_{\mathrm{Tot}}\right)^{-7.5}$ is the backward rate of the permissive to non-permissive transition. There are two types forces: active force and passive force. The active force created by contraction of the cross-bridge, and the passive force improves the complete muscle response with titin and other cytoskeletal elements. Mass prevents prompt changes in muscle-shortening velocity for quick-release protocols. Series elastic element represents effects of compliant end connections on real muscle preparations

\section{Model of human ventricular cells based on electrophysiology}

We used the Ten Tusscher model for human ventricular cells, which has electrophysiological characteristics consisting of a lumped parameter circuit that mimics the ion exchange phenomenon through the cell membrane of a myocyte $[17,18]$. The electrophysiology behavior of a ventricular cell can be expressed by the following differential equation:

$$
\frac{\mathrm{d} V_{\mathrm{m}}}{\mathrm{d} t}=-\frac{I_{\mathrm{ion}}+I_{\mathrm{stim}}}{C_{\mathrm{m}}}
$$


where $V_{\mathrm{m}}$ is the cell membrane potential, $t$ is the time, $I_{\text {stim }}$ is the current due to external stimuli, and $C_{\mathrm{m}}$ is the capacitance of the cell membrane. $I_{\text {ion }}$ denotes the sum of all transmembrane ionic currents expressed by the following equation:

$$
\begin{aligned}
I_{\mathrm{ion}}= & I_{\mathrm{Na}}+I_{\mathrm{K} 1}+I_{\mathrm{to}}+I_{\mathrm{Kr}}+I_{\mathrm{Ks}} \\
& +I_{\mathrm{CaL}}+I_{\mathrm{NaCa}}+I_{\mathrm{NaK}}+I_{\mathrm{pCa}} \\
& +I_{\mathrm{pK}}+I_{\mathrm{bCa}}+I_{\mathrm{bNa}}
\end{aligned}
$$

where $I_{\mathrm{Na}}$ is the rapid inward $\mathrm{Na}^{+}$current, $I_{\mathrm{K} 1}$ is the inward rectifier $\mathrm{K}^{+}$current, $I_{\mathrm{to}}$ is the transient outward $\mathrm{K}^{+}$current, $I_{\mathrm{Kr}}$ is the rapid delayed rectifier $\mathrm{K}^{+}$current, $I_{\mathrm{Ks}}$ is the slow delayed rectifier $\mathrm{K}^{+}$current, $I_{\mathrm{CaL}}$ is the L-type $\mathrm{Ca}^{2+}$ current, $I_{\mathrm{NaCa}}$ is the $\mathrm{Na}^{+}-\mathrm{Ca}^{2+}$ exchanger current, $I_{\mathrm{NaK}}$ is the $\mathrm{Na}^{+}-\mathrm{K}^{+}$pump current, $I_{\mathrm{pCa}}$ is the plateau $\mathrm{Ca}^{2+}$ pump current, $I_{\mathrm{pK}}$ is the plateau $\mathrm{K}^{+}$pump current, $I_{\mathrm{bCa}}$ is the background $\mathrm{Ca}^{2+}$ current, and $I_{\mathrm{bNa}}$ is the background $\mathrm{Na}^{+}$current.

Calcium dynamics for the calculation of calcium transients can be described with the following equation:

$$
\begin{aligned}
& I_{\text {leak }}=V_{\text {leak }}\left(\mathrm{Ca}_{\mathrm{SR}}-\mathrm{Ca}_{\mathrm{i}}\right) \\
& I_{\text {up }}=\frac{V_{\text {maxup }}}{1+K_{\mathrm{up}}^{2} / \mathrm{Ca}_{\mathrm{i}}^{2}} \\
& I_{\text {rel }}=V_{\text {rel }} O\left(\mathrm{Ca}_{\mathrm{SR}}-\mathrm{Ca}_{\mathrm{ss}}\right) \\
& I_{\text {xfer }}=V_{\text {xfer }}\left(\mathrm{Ca} \mathrm{SS}-\mathrm{Ca}_{\mathrm{i}}\right) \\
& \frac{\mathrm{dCa} \text { itotal }}{\mathrm{d} t}=-\frac{I_{\mathrm{bCa}}+I_{\mathrm{pCa}}-2 I_{\mathrm{NaCa}}}{2 V_{\mathrm{C}} F} \\
& \quad+\frac{V_{\text {sr }}}{V_{\mathrm{c}}}\left(I_{\text {leak }}-I_{\text {up }}\right)+I_{\text {rel }}
\end{aligned}
$$

where $I_{\text {leak }}, I_{\text {up }}, I_{\text {rel }}$, and $I_{\text {xfer }}$ denote the leakage current from SR to the cytoplasm, pump current taking up calcium in SR, calcium-induced calcium-released current, and diffusive $\mathrm{Ca}^{2+}$ current between dyadic $\mathrm{Ca}^{2+}$ subspace and bulk cytoplasm, respectively. $\mathrm{Ca}_{\mathrm{i}}$, $\mathrm{Ca}_{\mathrm{sr}}$, and $\mathrm{Ca}_{\mathrm{sS}}$ are the free cytoplasmic calcium concentration, free SR calcium concentration, and free dyadic subspace calcium concentration, respectively. $V_{\text {leak}}, V_{\text {maxup }}, V_{\text {rel }}$, and $V_{\text {xfer }}$ are the maximal $I_{\text {leak }}, I_{\text {up }}, I_{\text {rel }}$, and $I_{\text {xfer }}$, respectively. $O$ is the ratio of open $I_{\text {rel }}$ channels. $\mathrm{Ca}_{\text {itotal }}$ represents the total (free + buffered) cytoplasmic $\mathrm{Ca}^{2+}$ concentration. $V_{\mathrm{c}}$ and $V_{\mathrm{sr}}$ are the volume of the cytoplasm and sarcoplasmic reticulum, respectively. $F$ is the Faraday constant.

We implemented each ventricular cell such as endocardial cell, mid-myocardial cell, and epicardial cell, with different conductance of ion channels. Please refer to Ten Tusscher et al. $[17,18]$ for details on each Eqs. (1-7).

\section{Model of the cardiac myofilament}

We used the Rice model, which implemented the cardiac myofilament, to simulate the mechanical responses of cross-bridge cycling under isometric and isotonic 
contraction. The normalized active force of myocytes can be expressed by the following equation:

$$
F_{\text {active }}(x)=\operatorname{SOVF}_{\text {thick }}(x) \frac{x \mathrm{XB}_{\text {PreR }} \mathrm{XB}_{\text {PreR }}+x \mathrm{XB}_{\text {PostR }} \mathrm{XB}_{\text {PostR }}}{x_{0} \mathrm{XB}_{\text {PostR }}^{\mathrm{Max}}}
$$

where $x$ is the sarcomere length, $\operatorname{SOVF}_{\text {thick }}(x)$ is the single-overlap fraction of the thick filament, and $x_{0}$ is the mean strain of strongly-bound state. $\mathrm{XB}_{\mathrm{PostR}}^{\mathrm{Max}}$ are the scaling factors for state occupancy computed under optimal conditions, which indicates the fraction of strongly-bound cross-bridges. $\mathrm{XB}_{\mathrm{PreR}}$ is the probability that the cross-bridge is in the pre-rotated force-generating state while $\mathrm{XB}_{\text {PostR }}$ is the probability that the crossbridge is in the post-rotated force-generating state. The total ATP consumption, which includes strain-dependent terms, can be expressed by the following equation:

$$
\mathrm{ATP}=g_{\mathrm{xbT}} \mathrm{XB}_{\text {PostR }} \operatorname{SOVF}_{\text {thick }}(x)
$$

where, $g_{\mathrm{xbT}}$ is the detachment rate of the cross-bridge. The sarcomere length can be expressed by the following equation:

$$
\frac{\mathrm{d}}{\mathrm{d} t} \mathrm{SL}=\frac{\text { Integral }_{\text {Force }}+\left(\mathrm{SL}_{0}-\mathrm{SL}\right) \times \text { viscosity }}{\text { mass }}
$$

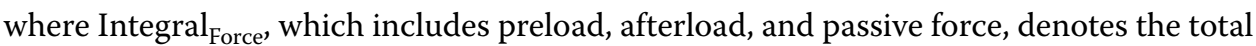
amount of normalized force over time. The viscosity is the viscous factor for calculating the complete muscle response. In the isosarcometric condition, $\frac{\mathrm{d}}{\mathrm{d} t} \mathrm{SL}=0$ and $\mathrm{SL}$ is constant as the initial value $\mathrm{SL}_{0}$. Please refer to Rice et al. [19] for details on each Eqs. (8-10).

\section{Simulation protocols}

\section{Electrical simulation}

We simulated three types of human ventricular cells: endocardial cell, mid-myocardial cell, and epicardial cell. To obtain the APD restitution curve, we reduced the BCL from 1000 to $200 \mathrm{~ms}$ in $30 \mathrm{~ms}$ increments. Each cycle was repeated 30 times to obtain steady-state data, and the 29th and 30th data were used for Table 1. In the Ten Tusscher model [18], it was found that alternans occurred when the restitution slope was higher than 1. Thus, we set the APD slope as 1.8 to cause severe alternans.

\section{Mechanical simulation}

To implement E-C coupling, we used data on calcium transient, which is the output data of electrical simulation, as the input data of mechanical simulation. We set the loads applied to ventricular cells as $10 \mathrm{kPa}\left(\mathrm{mN} / \mathrm{mm}^{2}\right)$ and $1000 \mathrm{kPa}$ for implementation of isotonic contraction and isometric contraction, respectively. We also set the load as $0.6 \mathrm{kPa}$, which is the minimum value for precise calculation with our isotonic model to quantitatively determine the impact of loads under isotonic contraction.

\section{Results}

The quantitative data associated with Figs. 2, 3, 4, 5, 6 are listed in Table 1. 
Table 1 The quantitative values corresponding to Figs. 2, 3, 4, 5, 6

\begin{tabular}{|c|c|c|c|c|c|c|c|c|c|c|c|}
\hline \multirow[t]{2}{*}{ Cell type } & \multirow[t]{2}{*}{$\mathrm{BCL}(\mathrm{ms})$} & \multirow[t]{2}{*}{ APD (ms) } & \multicolumn{2}{|c|}{$\mathrm{Ca}^{2+}(\mu \mathrm{M})$} & \multicolumn{2}{|c|}{$\mathrm{ST}(\mathrm{kPa})$} & \multicolumn{2}{|c|}{ DT (kPa) } & \multicolumn{2}{|c|}{ TPT (ms) } & \multirow{2}{*}{$\begin{array}{l}\text { SL } \\
\text { IM }\end{array}$} \\
\hline & & & Max & Min & IM & IT_10 & IM & IT_10 & IM & IT_10 & \\
\hline \multirow[t]{6}{*}{ Endo } & 1000 (30th) & 286 & 0.73 & 0.098 & 15 & 10 & 0 & 0 & 228 & 152 & 1 \\
\hline & 280 (30th) & 203 & 1.087 & 0.237 & 99 & 10 & 62 & - & 128 & - & 1 \\
\hline & 280 (29th) & 203 & 1.087 & 0.237 & 99 & 10 & 62 & - & 128 & - & 1 \\
\hline & 200 (30th) & 136 & 1.027 & 0.34 & 98 & 10 & 80 & - & 118 & - & 1 \\
\hline & 200 (29th) & 189 & 0.976 & 0.324 & 97 & 10 & 81 & - & 120 & - & 1 \\
\hline & 600 (30th) & 276 & 1.211 & 0.124 & 97 & 10 & 3 & 2 & 170 & 66 & 1 \\
\hline \multirow[t]{6}{*}{ M } & 1000 (30th) & 360 & 1.071 & 0.108 & 79 & 10 & 0 & 0 & 190 & 70 & 1 \\
\hline & 280 (30th) & 183 & 1.109 & 0.243 & 97 & 10 & 57 & - & 132 & - & 1 \\
\hline & 280 (29th) & 267 & 1.004 & 0.216 & 96 & 10 & 54 & - & 134 & - & 1 \\
\hline & 200 (30th) & 285 & 1.378 & 0.184 & 100 & 10 & 36 & - & 134 & - & 1 \\
\hline & 200 (29th) & 285 & 1.378 & 0.184 & 100 & 10 & 36 & - & 134 & - & 1 \\
\hline & 760 (30th) & 351 & 1.471 & 0.122 & 99 & 10 & 1 & 1 & 158 & 64 & 1 \\
\hline \multirow[t]{6}{*}{ Epi } & 1000 (30th) & 287 & 0.78 & 0.099 & 22 & 10 & 0 & 0 & 222 & 122 & 1 \\
\hline & 280 (30th) & 201 & 1.063 & 0.231 & 97 & 10 & 59 & - & 130 & - & 1 \\
\hline & 280 (29th) & 201 & 1.063 & 0.231 & 97 & 10 & 59 & - & 130 & - & 1 \\
\hline & 200 (30th) & 136 & 0.976 & 0.324 & 96 & 10 & 77 & - & 118 & - & 1 \\
\hline & 200 (29th) & 187 & 0.903 & 0.29 & 95 & 10 & 77 & - & 124 & - & 1 \\
\hline & 620 (30th) & 277 & 1.285 & 0.125 & 98 & 10 & 3 & 2 & 164 & 64 & 1 \\
\hline \multirow[t]{2}{*}{ Cell type } & \multicolumn{2}{|l|}{ SL } & \multicolumn{2}{|l|}{$\mathrm{DL}$} & \multicolumn{3}{|c|}{ TPL (ms) } & \multicolumn{2}{|l|}{ ATP } & \multicolumn{2}{|c|}{ TPA (ms) } \\
\hline & IT_10 & IT_0.6 & IT_10 & IT_0.6 & $\mathrm{IM}$ & IT_10 & IT_0.6 & IM & IT_10 & IM & IT_10 \\
\hline \multirow[t]{6}{*}{ Endo } & 0.957 & 0.774 & 1 & 1 & - & 234 & 172 & 0.14 & 0.119 & 228 & 186 \\
\hline & 0.751 & 0.7 & 0.913 & 0.813 & - & 130 & 116 & 0.913 & 0.419 & 128 & 78 \\
\hline & 0.751 & 0.7 & 0.913 & 0.813 & - & 130 & 116 & 0.913 & 0.419 & 128 & 78 \\
\hline & 0.769 & 0.71 & 0.863 & 0.786 & - & 122 & 118 & 0.911 & 0.213 & 118 & 80 \\
\hline & 0.78 & 0.72 & 0.865 & 0.788 & - & 120 & 120 & 0.9 & 0.19 & 120 & 78 \\
\hline & 0.74 & 0.661 & 1 & 0.960 & - & 170 & 142 & 0.9 & 0.79 & 170 & 110 \\
\hline \multirow[t]{6}{*}{ M } & 0.789 & 0.683 & 1 & 1 & - & 170 & 144 & 0.736 & 0.441 & 190 & 112 \\
\hline & 0.751 & 0.7 & 0.920 & 0.813 & - & 140 & 124 & 0.908 & 0.447 & 132 & 88 \\
\hline & 0.762 & 0.713 & 0.936 & 0.821 & - & 134 & 118 & 0.89 & 0.446 & 134 & 82 \\
\hline & 0.715 & 0.666 & 0.987 & 0.839 & - & 152 & 120 & 0.93 & 1 & 134 & 88 \\
\hline & 0.715 & 0.666 & 0.987 & 0.839 & - & 152 & 120 & 0.93 & 1 & 134 & 88 \\
\hline & 0.716 & 0.643 & 1 & 1 & - & 168 & 144 & 0.925 & 1.038 & 158 & 104 \\
\hline \multirow[t]{6}{*}{ Epi } & 0.919 & 0.76 & 1 & 1 & - & 218 & 164 & 0.207 & 0.147 & 222 & 160 \\
\hline & 0.754 & 0.704 & 0.923 & 0.816 & - & 132 & 116 & 0.907 & 0.439 & 130 & 80 \\
\hline & 0.754 & 0.704 & 0.923 & 0.816 & - & 132 & 116 & 0.907 & 0.439 & 130 & 80 \\
\hline & 0.777 & 0.717 & 0.868 & 0.790 & - & 120 & 116 & 0.899 & 0.204 & 118 & 76 \\
\hline & 0.787 & 0.725 & 0.872 & 0.793 & - & 122 & 122 & 0.886 & 0.19 & 124 & 78 \\
\hline & 0.731 & 0.654 & 1 & 0.964 & - & 198 & 140 & 0.912 & 0.877 & 164 & 106 \\
\hline
\end{tabular}

ST systolic tension, DT diastolic tension, TPT time of peak tension, SL systolic length, DL diastolic length, TPL time of peak length, TPA time of peak ATP, IM isometric, IT_10 isotonic (load=10 kPa), IT_0.6 isotonic (load =0.6 kPa)

\section{Results of electrical simulation according to decreasing of $\mathrm{BCL}$}

Figure 2 shows changes in APD with decreasing BCL from 1000 to $200 \mathrm{~ms}$. The electrical alternans of endocardial cell, mid-myocardial cell, and epicardial cell started at $258 \mathrm{~ms}, 340 \mathrm{~ms}$, and $244 \mathrm{~ms}$, respectively. When the BCL of mid-myocardial cell 


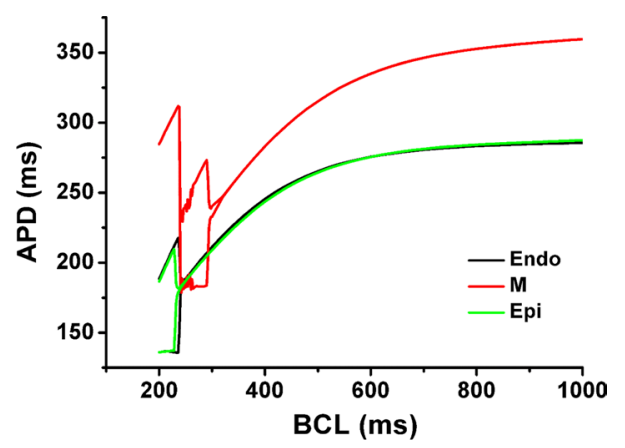

Fig. 2 Changes in action potential duration (APD) according to basic cycle length (BCL) for each ventricular cell. Endo is the endocardial cell, $\mathrm{M}$ is the mid-myocardial cell, and Epi is the epicardial cell

decreased to $238 \mathrm{~ms}$, the next stimulus was ignored by the relative refractory period so it seems like APD increased.

Figure 3 represents the membrane potential and calcium transient of endocardial cell (a), mid-myocardial cell (b), and epicardial cell (c) for $1 \mathrm{~s}$ according to specific BCL of ventricular cells. We set BCL as $1000 \mathrm{~ms}, 280 \mathrm{~ms}$ when the electrical alternans of midmyocardial cell occurs, and $200 \mathrm{~ms}$ when the electrical alternans of endocardial cell and epicardial cell occur. The APD and $\mathrm{Ca}^{2+}$ transient at BCL of $1000 \mathrm{~ms}$ were larger in the order of mid-myocardial cell, epicardial cell, and endocardial cell; and discordant (outof-phase) alternans between membrane potential and $\mathrm{Ca}^{2+}$ transient was observed in all three ventricular cells (Fig. 3a-c). As BCL decreased, $\mathrm{Ca}^{2+}$ transient increased (Fig. 3a, c). As shown in Fig. 2, when the BCL of mid-myocardial cell is $200 \mathrm{~ms}$, the APD and maximum $\mathrm{Ca}^{2+}$ transient increased compared with BCL of $280 \mathrm{~ms}$ (Fig. 3b). In addition, we found that the electrical alternans of ventricular cells had APD/BCL higher than 0.9 but less than 1 (Fig. 3 and Table 1).

\section{Results of mechanical simulation as decreasing of $\mathrm{BCL}$}

Figure 4 illustrates the result of mechanical simulation using the $\mathrm{Ca}^{2+}$ transient, which is the output data from electrical simulation. Myocardial tension and contractile ATP consumption rate were observed/found under isometric and isotonic conditions. Endocardial cell, mid-myocardial cell, and epicardial cell were compared to determine the maximum ATP consumption rate; then, we normalized the maximum value as 1 (see Fig. 4d). Under isometric condition (Fig. 4a, c, e), the systolic tension was larger and the time of peak systolic tension was faster in the order of mid-myocardial cell, epicardial cell, and endocardial cell, when BCL was 1000 ms. Specific BCL (mid-myocardial cell: $280 \mathrm{~ms}$, endocardial cell, and epicardial cell: $200 \mathrm{~ms}$ ), when occurred electrical and $\mathrm{Ca}^{2+}$ transient alternans (Fig. 3), also showed mechanical alternans, which means alternans of myocardial tension and contractile ATP consumption. Under isotonic condition (Fig. 4b, $\mathrm{d}, \mathrm{f}$ ), the time of peak systolic tension was fast and the duration of systolic tension was long in the order of mid-myocardial cell, epicardial cell, and endocardial cell when BCL was $1000 \mathrm{~ms}$. When the BCL of all ventricular cells was 280 and $200 \mathrm{~ms}$, systolic tension was constant as the load value regardless of the $\mathrm{Ca}^{2+}$ transient and contractile ATP consumption rates. When the BCL of mid-myocardial cell was $200 \mathrm{~ms}$, the amplitude of 


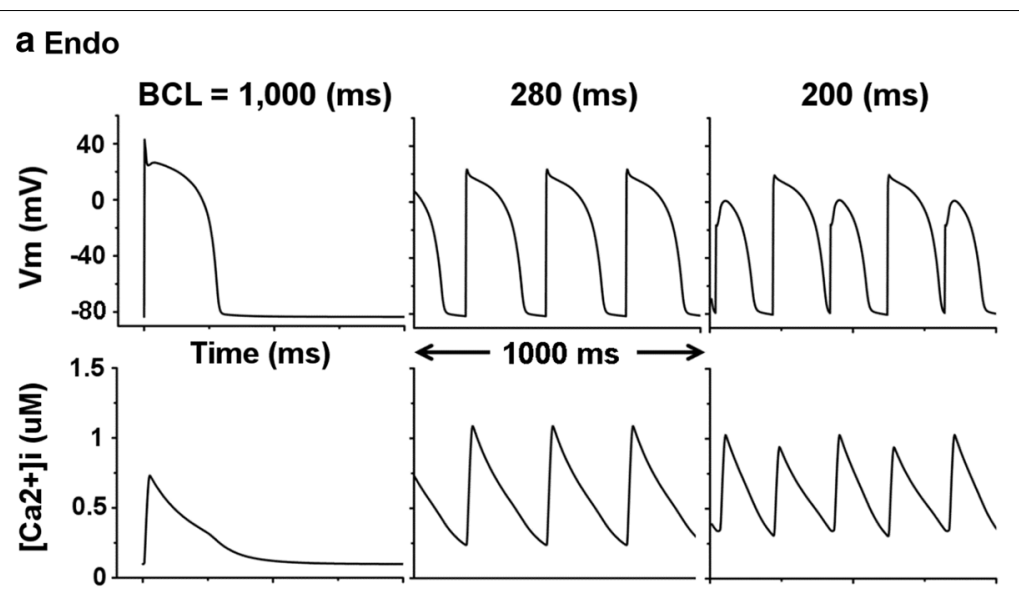

b $\mathbf{M}$
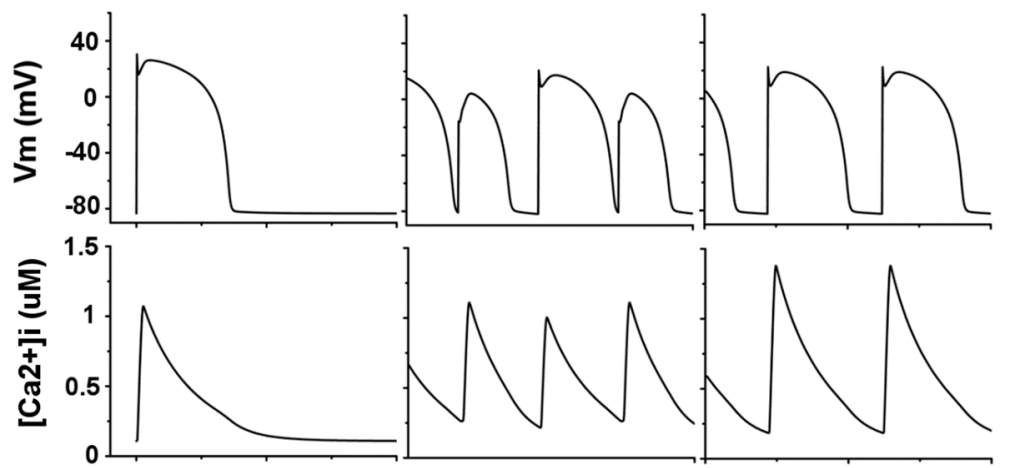

C Epi
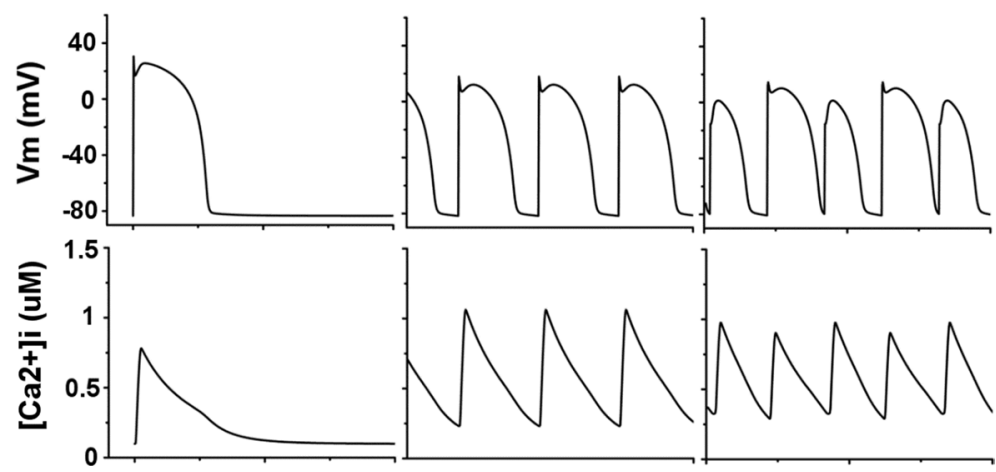

Fig. 3 Electrical simulations of membrane potential and intracellular calcium concentration. a-c Cases of Endo, M, and Epi, respectively for $1 \mathrm{~s}$. Each figure is divided into three cases according to different BCLs (1000 ms, 280 ms when electrical alternans occur under Endo and Epi conditions; and 200 ms when electrical alternans appear under $\mathrm{M}$ condition)

myocardial tension and contractile ATP consumption rate increased, and the refractory period of the cardiac cycle became longer (Fig. 4c, d). Overall, the maximum contractile ATP consumption rate decreased and the minimum contractile ATP consumption rate was greater than 0 when mechanical alternans occurred.

Figure 5 shows the equivalent cell length of isotonic contraction under $10 \mathrm{kPa}$ and $0.6 \mathrm{kPa}$ conditions at three different BCLs (Fig. 5a, c, e) as well as the total time from 


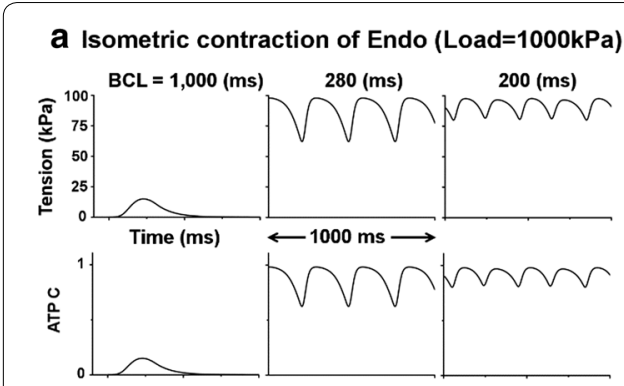

b Isotonic contraction of Endo (Load=10kPa)
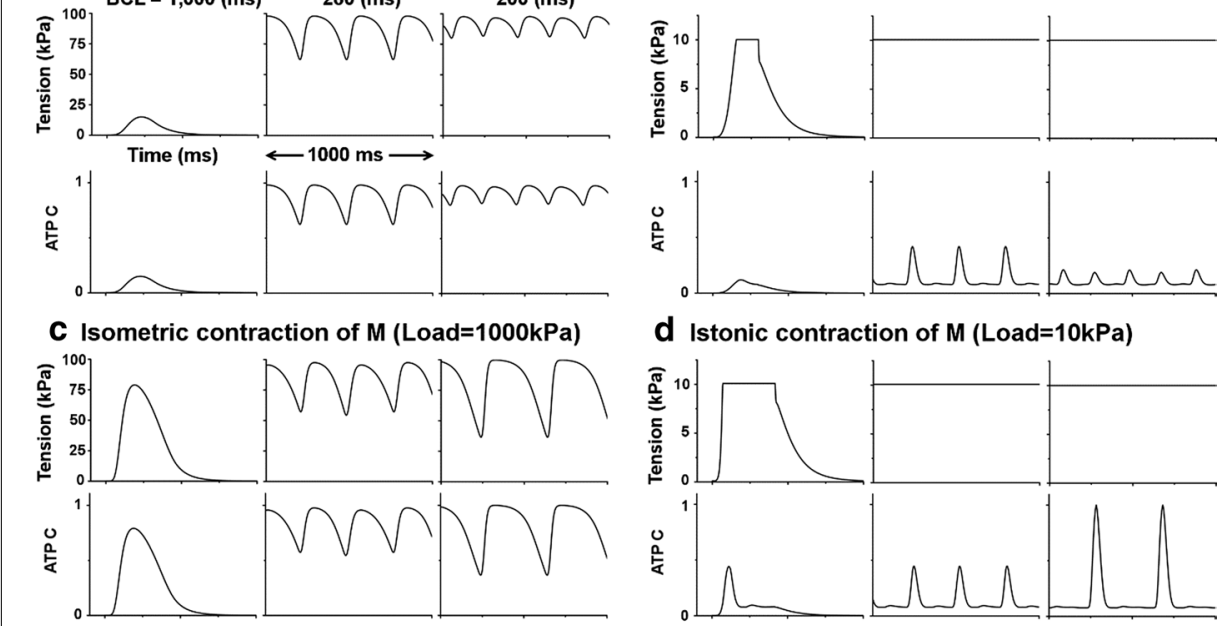

d Istonic contraction of $\mathrm{M}(\mathrm{Load}=10 \mathrm{kPa})$

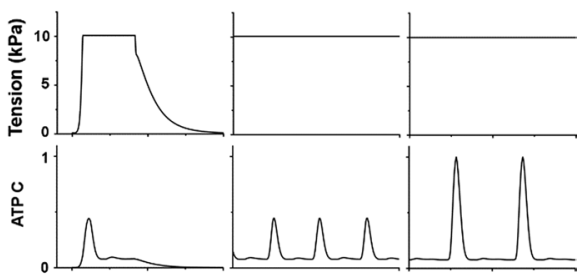

e Isometric contraction of Epi (Load $=1000 \mathrm{kPa})$
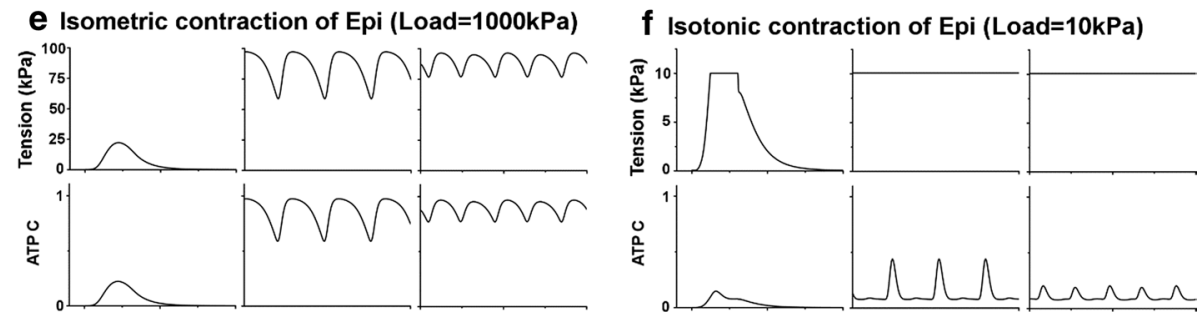

Fig. 4 Mechanical simulations of myocardial tension and contractile ATP consumption rate. The left side represents the results of isometric contraction when the load is $1000 \mathrm{kPa}\left(\mathrm{mN} / \mathrm{mm}^{2}\right)$ and the right side shows isotonic contraction when the load is $10 \mathrm{kPa}$

BCL of $1000 \mathrm{~ms}$ to $200 \mathrm{~ms}$ (Fig. 5b, d, f). In all three ventricular cells, systolic length was short in the order of mid-myocardial cell, epicardial cell, and endocardial cell regardless of load. Diastolic length was not relaxed to 1 (100\%) when BCL was 280 and $200 \mathrm{~ms}$ (Fig. 5a, c, e). When the load of ventricle cells was $0.6 \mathrm{kPa}$ compared with the $10 \mathrm{kPa}$ condition as BCL decreased, the specific BCL (arrow in Fig. 5b, d, f), which showed the starting point at which diastolic length was not relaxed to 1 was higher and the systolic length was always shorter (Fig. 5b, d, f).

Figure 6 shows the amplitude and maximum value of myocardial tension with decreasing BCL under isometric condition. As BCL decreased, the amplitude of tension and the peak of systolic tension increased. When the BCL of endocardial cell, mid-myocardial cell, and epicardial cell exceeded 600, 760 and $620 \mathrm{~ms}$, respectively, the amplitude was highest and then decreased, and the peak value remained high. The timing of alternans in myocardial tension was the same as when electrical alternans occurred (Fig. 2).

\section{Discussion}

In the present study, we used an excitation-contraction coupling model of human ventricular cells to quantitatively analyze the electromechanical responses with discordant electromechanical alternans according to decreasing of BCL from 1000 to $200 \mathrm{~ms}$. The main findings are as follows: 

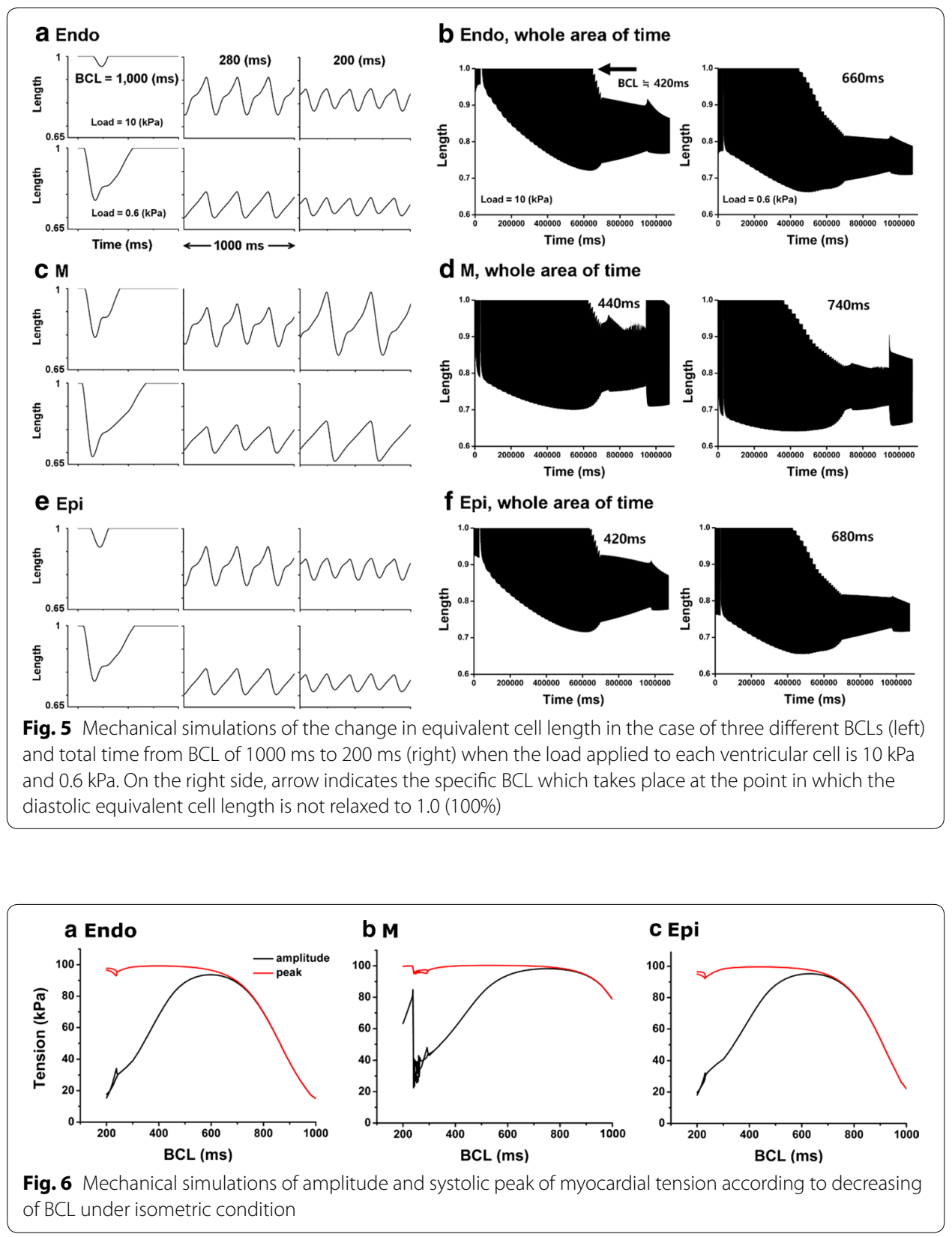

1. As the BCL of the ventricular myocytes decreased, the out-of-phase (discordant) alternans between membrane potential and $\mathrm{Ca}^{2+}$ transient occurred in the order of mid-myocardial cell, endocardial cell, and epicardial cell. Mechanical alternans such as alternans of myocardial tension, contractile ATP rate, and equivalent cell length were also observed (Figs. 2, 3, 4, 5, 6 and Table 1).

2. As the $\mathrm{BCL}$ of ventricular cells decreased, the minimum $\mathrm{Ca}^{2+}$ transient increased simultaneously with the occurrence/emergence of the electromechanical alternans of ventricular cells. Moreover, myocardial diastolic tension also increased and contractile ATP consumption rate was greater than 0 under isometric condition (Figs. 2, 3, 4 and Table 1). 
3. When mechanical alternans occurred $(B C L=200 \mathrm{~ms})$ under isotonic contraction, the variations in sarcomere length and contractile ATP consumption rate were smaller than in the case of no alternans $(B C L=280 \mathrm{~ms})$, except the mid-myocardial cell cell (Figs. 4, 5 and Table 1).

4. From a specific BCL (arrow in Fig. 5b, d, f), the equivalent cell length was not relaxed to $1(100 \%)$ and the systolic tension was always fixed at the same value as the load under isotonic condition. When the load was low, specific BCLs appeared faster and systolic length was always shorter (Figs. 4, 5 and Table 1).

5. Under isometric condition with decreasing BCL, the amplitude of tension was largest at BCL of $600 \mathrm{~ms}$ (endocardial cell), $760 \mathrm{~ms}$ (mid-myocardial cell), and $620 \mathrm{~ms}$ (epicardial cell), and the peak of systolic tension began to appear at a high rate (Fig. 6 and Table 1).

Ventricular tissue consists of three tissue structures, namely, endocardium, mid-myocardium, and epicardium. These tissues have different electrophysiological characteristics based on their structures [23]. For example, endocardium, the outermost layer of the heart, provides essential signals, such as Hedgehog signal for the continued growth and differentiation of the heart [24] and regulates the neighboring cardiac outflow tract $[25,26]$. In addition, the activation of growth factors and trans-differentiation of fibroblasts and immunocytochemical characterizations vary according to the endocardium, mid-myocardium, and epicardium [27]. microRNA is involved in the regeneration of epicardium from cardiovascular disorders [28-30]. The adult cardiac stem cells are multipotent and participate in the regeneration of mid-myocardium [31, 32]. Therefore, it is necessary to observe the mechanical response of cardiac alternans in the endocardial cell, mid-myocardial, and epicardial cells of the ventricular tissue, respectively.

The electrical instability of ventricular cells led to mechanical instability because mechanical alternans such as alternans of myocardial tension, contractile ATP rate, and equivalent cell length also occurred when BCL was $280 \mathrm{~ms}$ and $200 \mathrm{~ms}$, which was same timing as when discordant electrical alternans occurred (Figs. 2, 3, 4, 5, 6 and Table 1). Eventually, this will lead to the failure of ventricular mechanics at the organ level; for instance, a decrease in left ventricular ejection fraction [14-16].

In myocardial tissue cells with reduced BCL below a certain level, alternans are more likely to develop than in the normal BCL cells. This is because, the myocardial cells with short BCL do not have enough refractory period and diastolic interval as shown in Fig. 2 (refer $[1,2])$. When a discordant electrical alternans occur, a reduced diastolic interval lowers the cytosolic $\mathrm{Ca}^{2+}$ sequestration. This results in elevated free $\mathrm{Ca}^{2+}$ concentration in the cytosol (Fig. 3 and Table 1). This is again consistent with the fact that reduced capability of $\mathrm{Ca}^{2+}$ sequestration in the cytosol is related to the development of alternans $[10,12]$.

Myocardial diastolic tension increased with elevated minimum $\mathrm{Ca}^{2+}$ transient. When myocardial cell with normal BCL was contracted, rate of contractile ATP consumption is 0 during resting state. However, in case of mechanical alternans, contractile ATP consumption rate is always greater than 0 even resting state. This suggests that when mechanical alternans occurs at low BCL, the unstable state of ventricular cells can occur because of the continuous detachment of the cross-bridge (Fig. 4 and Table 1). 
In endocardial and epicardial cells, reduced $\mathrm{Ca}^{2+}$ transient due to mechanical alternans lowers contractile ATP consumption rate as compared to the state without mechanical alternans. It results in a reduction of the difference between the systolic and diastolic length (Figs. 4b, f, 5a, e). Similar to endocardial cell and epicardial cell, midmyocardial cell also has smaller changes in equivalent cell length and contractile ATP consumption rate compared with before the occurrence of electromechanical alternans (BCL $>340 \mathrm{~ms}$ in Fig. 2). However, this was not shown in the graph to avoid complexity.

Under isotonic contraction, the ventricular cells from the specific BCL (marked by arrows in Fig. 5b, d, f) are not completely relaxed, in which the equivalent length of the cells is not one. It is because the myosin head always forms a cross-bridge even with a higher load regardless of the sarcomere length without double overlap of the thin filament. Therefore, the systolic tension is the same as that of the load (Figs. 4, 5 and Table 1). During isotonic contraction, the lighter is the load of the ventricular cells, the lower is the rate of cross-bridge formation and the greater is the minimum BCL at which the cells are completely relaxed. Hence, when the load of the ventricular cells was $0.6 \mathrm{kPa}$ during isotonic contraction, the minimum BCL was longer than $10 \mathrm{kPa}$ load (marked by arrows in Fig. 5b, d, f). Thus, if the load of ventricular cells is low under isotonic condition, the unstable state occurs as BCL decreased. In addition, the change in sarcomere length is inversely proportional to the load (see Eq. 10). Thus, when load of ventricular cells is small, the systolic equivalent cell length is shorter than under the condition of high load (Fig. 5 and Table 1).

Under isometric condition, the peak systolic tension remained high and the amplitude of tension was highest at the specific BCL without mechanical alternans. It is possible to predict the amount of BCL given to each ventricular cell to generate the most efficient and stable tension (Fig. 6 and Table 1).

\section{Limitations}

This study has several limitations. First, experimental or clinical data were not collected as part of this study. Instead, the validated ventricular cell model and methodologies from previous studies were applied, such as the model of human ventricular cells [17, 18] and myofilament dynamics [19]. Second, we used the one-way EC coupling model to prevent the mechanical activity of ventricular cells from affecting the electrophysiological behavior of the heart, although such phenomena could occur physiologically. Finally, we simplified only the three-state cross-bridge cycle using the Rice model [19], but there are many more states in biochemical studies. In order to overcome the limitations, we will need to have more clinical data for validation of the model and apply more sophisticated numerical method for full E-C coupling.

\section{Conclusion}

As the BCL decreased, mechanical alternans (myocardial tension, contractile ATP consumption rate, and equivalent cell length) occurred as well as out-of-phase alternans between membrane potential and $\mathrm{Ca}^{2+}$. Simultaneously, myocardial diastolic tension increased and contractile ATP consumption rate remained greater than 0. Moreover, the time of peak tension, equivalent cell length, and contractile ATP rate decreased. Under isotonic condition, when electromechanical alternans occurred, the changes in 
sarcomere length and contractile ATP consumption rate were reduced compared with before the occurrence of alternans. The unstable state, in which cross-bridge formation rate was the same as the load regardless of sarcomere length, appeared quickly when the load of ventricular cells was low. In addition, we can see the amount of BCL given to each ventricular cell to generate stable and high tension states in the case of isometric contraction.

\section{Authors' contributions}

This work is the product of intellectual work of the entire team. JIP contributed to the analytical methods used, simulation process, and writing the manuscript. KML contributed to research concept, simulation design, simulation source code, and writing of the manuscript. Both authors read and approved the final manuscript.

\section{Funding}

This research was partially supported by the MSIT (Ministry of Science, ICT), under the ITRC (Information Technology Research Center) support program (IITP-2018-2014-0-00639) supervised by the IITP, and NRF (National Research Foundation) under basic engineering research project (2016R1D1A1B0101440) and the EDISON (NRF-2011-0020576) Programs.

\section{Availability of data and materials \\ Not applicable.}

Ethics approval and consent to participate

Not applicable.

\section{Consent for publication}

Not applicable.

\section{Competing interests}

The authors declare that they have no competing interests.

Received: 26 February 2019 Accepted: 27 May 2019

Published online: 07 June 2019

\section{References}

1. Banville I, Gray RA. Effect of APD and CV restitution and their spatial dispersion on alternans and the stability of arrhythmias. J Cardiovasc Electrophysiol. 2002;13:1141-9. https://doi.org/10.1046/j.1540-8167.2002.01141.x.

2. Cherry EM, Fenton FH. Suppression of alternans and conduction blocks despite steep APD restitution: electrotonic, memory, and conduction velocity restitution effects. Am J Physiol Circ Physiol. 2004;286:H2332-41. https://doi. org/10.1152/ajpheart.00747.2003.

3. Watanabe MA, Fenton FH, Evans SJ, Hastings HM, Karma A. Mechanisms for discordant alternans. J Cardiovasc Electrophysiol. 2001;12:196-206. https://doi.org/10.1046/j.1540-8167.2001.00196.x.

4. Pastore JM, Girouard SD, Laurita KR, Akar FG, Rosenbaum DS. Mechanism linking T-wave alternans to the genesis of cardiac fibrillation. Circulation. 1999;99:1385-94.

5. Shiferaw $Y$, Karma A. Turing instability mediated by voltage and calcium diffusion in paced cardiac cells. Proc Natl Acad Sci. 2006:103:5670-5

6. Wilson LD, Rosenbaum DS. Mechanisms of arrythmogenic cardiac alternans. Europace. 2007;9(Suppl 6):77-82

7. Majumder R, Engels MC, de Vries AAF, Panfilov AV, Pijnappels DA. Islands of spatially discordant APD alternans underlie arrhythmogenesis by promoting electrotonic dyssynchrony in models of fibrotic rat ventricular myocardium. Sci Rep. 2016:6:24334.

8. Narayan SM. T-wave alternans and the susceptibility to ventricular arrhythmias. J Am Coll Cardiol. 2006;47:269-81. https://doi.org/10.1016/j.jacc.2005.08.066.

9. Verrier RL, Klingenheben T, Malik M, El-Sherif N, Exner DV, Hohnloser SH, et al. Microvolt T-wave alternans: physiological basis, methods of measurement, and clinical utility - consensus guideline by International Society for Holter and noninvasive electrocardiology. J Am Coll Cardiol. 2011;58:1309-24.

10. Groenendaal W, Ortega FA, Krogh-Madsen T, Christini DJ. Voltage and calcium dynamics both underlie cellular alternans in cardiac myocytes. Biophys J. 2014;106:2222-32.

11. Jordan PN, Christini DJ. Characterizing the contribution of voltage- and calcium-dependent coupling to action potential stability: implications for repolarization alternans. Am J Physiol Circ Physiol. 2007;293:H2109-18.

12. Weiss JN, Karma A, Shiferaw Y, Chen P-S, Garfinkel A, Qu Z. From pulsus to pulseless. Circ Res. 2006;98:1244-53. https //doi.org/10.1161/01.RES.0000224540.97431.f0.

13. Edwards JN, Blatter LA. Cardiac alternans and intracellular calcium cycling. Clin Exp Pharmacol Physiol. 2014:41:524-32

14. Hirayama $Y$, Saitoh $H$, Atarashi $H$, Hayakawa $H$. Electrical and mechanical alternans in canine myocardium in vivo: dependence on intracellular calcium cycling. Circulation. 1993;88:2894-902.

15. Kodama M, Kato K, Hirono S, Okura Y, Hanawa H, Ito M, et al. Mechanical alternans in patients with chronic heart failure. J Card Fail. 2001;7:138-45 
16. Nishimura S, Yasuda S, Katoh M, Yamada KP, Yamashita H, Saeki Y, et al. Single cell mechanics of rat cardiomyocytes under isometric, unloaded, and physiologically loaded conditions. Am J Physiol Circ Physiol. 2004;287:H196-202. https://doi.org/10.1152/ajpheart.00948.2003.

17. Ten Tusscher KHWJ. A model for human ventricular tissue. AJP Heart Circ Physiol. 2004;286:H1573-89. https://doi. org/10.1152/ajpheart.00794.2003.

18. Ten Tusscher KHWJ, Panfilov AV. Alternans and spiral breakup in a human ventricular tissue model. Am J Physiol Circ Physiol. 2006;291:H1088-100.

19. Rice JJ, Wang F, Bers DM, De Tombe PP. Approximate model of cooperative activation and crossbridge cycling in cardiac muscle using ordinary differential equations. Biophys J. 2008;95:2368-90. https://doi.org/10.1529/bioph ysj.107.119487.

20. Jeong DU, Lim KM. Influence of the KCNQ1 S140G mutation on human ventricular arrhythmogenesis and pumping performance: simulation study. Front Physiol. 2018;9:1-14.

21. Lim KM, Constantino J, Gurev V, Zhu R, Shim EB, Trayanova NA. Comparison of the effects of continuous and pulsatile left ventricular-assist devices on ventricular unloading using a cardiac electromechanics model. J Physiol Sci. 2012;62:11-9.

22. Park JIK, Heikhmakhtiar AK, Kim CH, Kim YS, Choi SW, Song KS, et al. The effect of heart failure and left ventricular assist device treatment on right ventricular mechanics: a computational study. Biomed Eng Online. 2018;17:62.

23. Epicardial P, Cells M, Antzelevitch C, Sicouri S, Litovsky SH, Lukas A, et al. Brief review heterogeneity within the ventricular wall. Circ Res. 1991;69:1427-49.

24. Serluca FC. Development of the proepicardial organ in the zebrafish. Dev Biol. 2008;315:18-27. https://doi. org/10.1016/j.ydbio.2007.10.007.

25. Wang J, Cao J, Dickson AL, Poss KD. Epicardial regeneration is guided by cardiac outflow tract and Hedgehog signalling. Nature. 2015;522:226-30.

26. Peralta M, Steed E, Harlepp S, González-Rosa JM, Monduc F, Ariza-Cosano A, et al. Heartbeat-driven pericardiac fluid forces contribute to epicardium morphogenesis. Curr Biol. 2013;23:1726-35.

27. Romano N, Ceci M. The face of epicardial and endocardial derived cells in zebrafish. Exp Cell Res. 2018;369:166-75. https://doi.org/10.1016/j.yexcr.2018.05.022

28. Ceci M, Carlantoni C, Missinato MA, Bonvissuto D, Di Giacomo B, Contu R, et al. Micro RNAs are involved in activation of epicardium during zebrafish heart regeneration. Cell Death Discov. 2018;4:41.

29. Latronico MVG, Condorelli G. MicroRNAs and cardiac pathology. Nat Rev Cardiol. 2009;6:418-29. https://doi. org/10.1038/nrcardio.2009.56

30. Wagner KD, Wagner N, Bondke A, Nafz B, Flemming B, Theres H, et al. The Wilms'tumor suppressor. FASEB J. 2002;16:1.

31. Beltrami AP, Barlucchi L, Torella D, Baker M, Limana F, Chimenti S, et al. Adult cardiac stem cells are multipotent and support myocardial regeneration we have documented the existence of cycling ventricular myocytes in the normal and pathologic adult mammalian heart of several species, including humans (Kaj-stura et al., 1998. Cell. 2003;114:763-76.

32. Oh H, Bradfute SB, Gallardo TD, Nakamura T, Gaussin V, Mishina Y, et al. Cardiac progenitor cells from adult myocardium: homing, differentiation, and fusion after infarction. Proc Natl Acad Sci. 2003;100:12313-8.

\section{Publisher's Note}

Springer Nature remains neutral with regard to jurisdictional claims in published maps and institutional affiliations.

- fast, convenient online submission

- thorough peer review by experienced researchers in your field

- rapid publication on acceptance

- support for research data, including large and complex data types

- gold Open Access which fosters wider collaboration and increased citations

- maximum visibility for your research: over 100M website views per year

At BMC, research is always in progress.

Learn more biomedcentral.com/submissions 